\title{
Editors' declaration of their own conflicts of interest
}

\section{Irina Haivas, Sara Schroter, Fabian Waechter, Richard Smith}

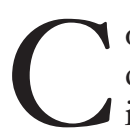
onflict of interest has been defined as a set of conditions in which professional judgement concerning a primary interest (such as patient welfare or the validity of research) can be influenced by a secondary interest (such as financial gain). ${ }^{1}$ The International Committee of Medical Journal Editors (ICMJE) acknowledges that anyone involved in the peer review and publication process, including editors, might have conflicts of interest. ${ }^{2}$ Although many journals now publish authors' financial conflicts of interest, and reviewers are asked to declare if they have a conflict of interest with regard to individual manuscripts, little is known about editors' conflicts of interest and the mechanisms to manage them.

Editors of high-impact biomedical journals have indicated that it is unacceptable for editors to have financial interests in commercial companies, ${ }^{3}$ and a few editorials have described journal policies regarding editors' conflicts of interests. ${ }^{46}$ However, editorial conflicts of interest can operate on many levels beyond financial interest: editors may entertain a dislike for certain authors; an author's work may compete with or contradict an editor's own work in the same field; or an editor, having decided not to publish a particular author's submission, may be tempted to pursue the same idea with others deemed to be more capable.

Editors are responsible for making the ultimate decision about publication, but who regulates them in doing so? To encourage greater transparency and raise awareness that editors are not impervious to bias, $B M 7$ now publicly declares the financial and nonfinancial conflicts of interest of its own editors and editorial board members. ${ }^{4}$ We were interested to know how willing other editors are to publicly declare their conflicts of interest, and to find out about current policies to protect authors from their potential effects.

We conducted a survey of journal editors to explore editorial policies toward conflicts of interest (financial and nonfinancial) of editors and other staff involved in manuscript decisions. In the absence of a published method for obtaining a representative and manageable sample of all medical journals, we focused on one important category, general and internal medicine, as an indicator for the overall situation. We used the ISI Web of Knowledge Journal Database Version 2001 (www.isiknowledge.com) to obtain a list of all 108 peerreviewed journals in this category. Using computer-generated random numbers, we took a random sample of 35 . Because top medical journals are commonly used to depict trends in scientific medical publishing, we also included a purposive sample of the top 5 US and 5 non-US journals in this category, ranked by impact factor. Five of these had already been selected through the random sampling, and so the total number of journals was 40 . Three journals were then excluded: 1 had insufficient contact details, and 2 had ceased publication We sent senior editors a questionnaire asking about their journal's declaration of conflicts of interest for editors, editorial board members and other editorial advisers; how important they felt it was to declare conflicts of interest; and whether they intended to publicly declare these in the future. We followed up with non-respondents by telephone.

We received a response from $30(81 \%)$ of the 37 journals. Of these, 19 (63\%) felt it was either important or very important to declare the financial conflicts of interest of their editors; 13 (43\%) felt that this was important for their editorial board members, and $11(37 \%)$ for other editorial advisers (see online Table at www.cmaj.ca/cgi /content/full/171/5/475/DC1). Seven (23\%) reported it was not important to declare editors' financial interests, and $4(13 \%)$ did not respond to this item. Eleven (37\%) reported that they do not intend to declare their editors' financial interests in the future, and $16(53 \%)$ do not intend to do so for their editorial board members or other editorial advisers. Reasons for not declaring these interests included statements that it is "unnecessary," that "editors do not have conflicts of interest" and that the "issue had never been considered."

Only $9(30 \%)$ stated they have an explicit policy to deal with editors' financial conflicts of interest; Box 1 lists elements that occur in most of these policies. (Only BMF publicly declares individuals' conflicts of interest on its $\mathrm{Web}$ site.) Journals with higher impact factors were more likely to have a policy on editors' financial conflicts of interest than journals with lower impact factors. Seven respondents (23\%) stated that they declare the nonfinancial conflicts of interest 
of their editors, $4(13 \%)$ declare such conflicts for their editorial board members and 4 (13\%) for other editorial advisers. However, there are few mechanisms in place to ensure that all declarations are updated, even where there is a policy of declaring these interests. It is often not made clear to readers exactly how some of these policies are implemented and how financial conflicts of interest are defined.

One limitation of our study is the focus on a single category of medicine. We are unsure how representative this category is of all medical journals. As we purposively included the top 5 US and 5 non-US journals in an influential category, it is possible that the results are an overestimate of current practice across all journals. As medical journals have led the way in introducing editorial policies to deal with conflicting intersts, ${ }^{2}$ it is likely that the situation is similar or worse in other scientific journals. We feel that all journals should have a policy to deal with these potential conflicts of interest; editors are not impervious to bias, and it is not acceptable to dismiss the issue as unimportant. There is a need for greater transparency for all journals, as editors should be accountable for decisions made about scientific research. However, even where policies are in place, we do not know how effective they are. The ICMJE and other publication bodies should meet to discuss the best approach to dealing with these issues.
From the BMF Editorial Office, BMA House, Tavistock Square, London, UK

Competing interests: All authors were affiliated with $B M 7$ at the time this article was written. Richard Smith was the editor of $B M 7$ and took part in the survey; he was responsible for devising $B M 7$ policy on competing interests. He was paid a fixed salary and was not affected financially by the success or failure of the policy. Sara Schroter, Fabian Waechter and Irina Haivas were employed by BMF while conducting this study.

Contributors: Richard Smith initiated the study; Sara Schroter, Irina Haivas and Fabian Waechter designed the study; and Irina Haivas conducted the study. All authors interpreted the results, assisted in writing and revising the paper, and gave final approval of the version to be published.

Acknowledgements: This study was funded by the BMJ Publishing Group's research budget.

\section{References}

1. Thompson DF. Understanding financial conflicts of interest. $N$ Engl 7 Med 1993:329(8):573-6.

2. International Committee of Medical Journal Editors. Separate statements: conflicts of interest. Available: www.icmje.org/\#conflicts (accessed 2004 May 28).

3. Van Kolfschooten F. Conflicts of interest: Can you believe what you read? Nature 2002;416:360-3.

4. Smith R. Making progress with competing interests. BM7 2002;325:1375-6.

5. James A, Horton R. The Lancet's policy on conflicts of interest. Lancet 2003;361:8-9.

6. Relman AS. Editor's reply to: Altman LK. Dealing with conflicts of interest [letter]. NEng 7 Med 1984;311:405.

Correspondence to: Dr. Sara Schroter, BMJ Editorial Office, BMA House, Tavistock Square, London WC1H 9JR, UK; sschroter@bmj.com

\section{CMAJ's Editorial Fellowship}

The CMAJ EditOrial Fellowship, launched in 1998, provides an exciting opportunity for physicians early in their training to discover the inner workings of a leading medical journal. Applications are invited from recent medical graduates and residents who are interested in obtaining a rich experience in medical writing, editing and publishing. The fellow participates in all aspects of journal production, ranging from deciding which manuscripts to publish and working with authors to soliciting commentaries and review articles. Fellows are also expected to write extensively and are encouraged to develop theme issues, series or other journal innovations.

The position is full time for one year and is based at CMAJ's offices in Ottawa. The salary is based on the equivalent residency remuneration in Ontario.

The next round of applications is for the 2005 fellowship, which begins July 1,2005 . The application deadline is December 15, 2004.

For more information, please contact Dr. John Hoey, Editor, at john.hoey@cma.ca.

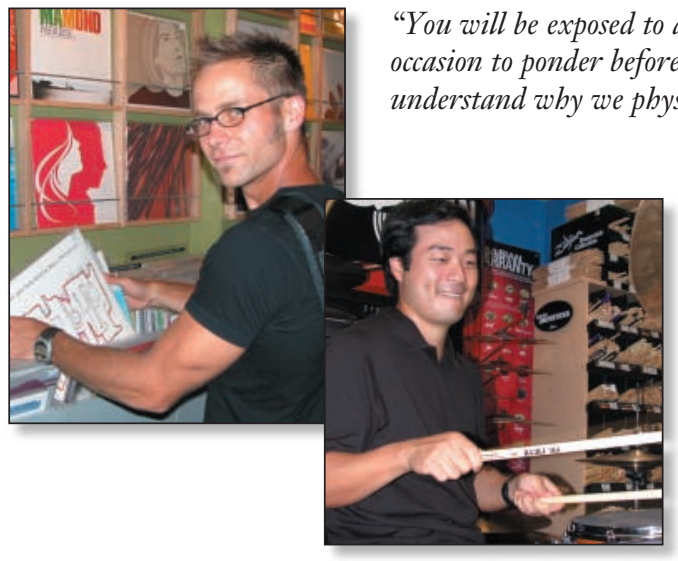

"You will be exposed to aspects of medicine that you never had occasion to ponder before. And, perhaps, you will better — James Maskalyk, fellow 2002

"The fellowship is an amazing opportunity to develop new skills and learn what it means to be an editor. Prepare yourself for an exciting year as you watch new developments in modern medicine unfold before your eyes and help shape how physicians interpret them."

- Steve Choi, fellow 2003 